\title{
Ovarian Ablation and Letrozole as Treatment for Premenopausal Women with Metastatic Breast Cancer
}

\author{
Hanan G. Mostafa \\ Department of Clinical Oncology and Nuclear Medicine, Faculty of Medicine, Assiut University \\ Hospital, Egypt
}

Purpose: To assess the efficacy and safety of ovarian ablation followed by letrozole as a first or second-line treatment for premenopausal women with metastatic breast cancer (MBC).

Patients and method: Premenopausal women with estrogen receptors and/or progesterone receptor positive $\mathrm{MBC}$, received ovarian ablation by radiotherapy (16Gy in 4 consecutive fractions) followed by letrozole tablets $2.5 \mathrm{mg}$ by mouth daily.

Results: Between May 2010 and March 2013 thirty-five patients were eligible and included in the study. Twenty-four patients $(68.6 \%)$ had bone metastases and half of patients $(n=18 ; 51.4 \%)$ had only one metastatic site. Twelve (34.3\%) patients achieved partial response (PR) and 11 had (31.4\%) stable disease (SD). The clinical benefit rate (PR+ SD) was 65.7\%. With a median duration of follow-up 24 months the median progression-free survival (PFS) was 7 months and the median overall survival was 18 months. Longer PFS was significantly observed in patients with one metastatic site, HER2/neu negative and longer disease-free interval when used as a first-line therapy. No serious toxicities secondary to letrozole or radiotherapy were reported.

Conclusion: The results suggest that ovarian ablation by radiotherapy followed by letrozole is an effective first-line treatment for premenopausal women with hormonal receptor positive MBC.

Key words: Endocrine Therapy, Letrozole, Metastatic Breast Cancer, Ovarian Ablation. Corresponding Author: Hanan G. Mostafa

E-mail: mostafahanan36@yahoo.com

\section{INTRODUCTION}

Breast cancer is less common among women below the age of 40 and almost two thirds of premenopausal breast cancer expresses estrogen receptors which is less than in postmenopausal ${ }^{1,2}$.

The selection of treatment in breast cancer patients depends on the stage, the biological characteristics like hormonal receptor and HER-2 status and the presence or absence of co-morbidities ${ }^{3}$.

For patients with metastatic breast cancer (MBC), the main aim of anti-cancer treatment is to control the tumor as well as symptoms taking into consideration the efficacy and tolerability of the treatment and its impact on the quality of life. Considering these factors, hormonal therapy for hormone positive breast cancer patients would be a preferred choice ${ }^{4}$.

One of the effective endocrine therapy options in hormone positive premenopausal $\mathrm{MBC}$ is ovarian ablation/suppression with or without tamoxifen/ aromatase inhibitors ${ }^{5}$. Ovarian ablation may be achieved by oophorectomy or ovarian irradiation and ovarian suppression by the use of luteinizing hormone-releasing hormone (LHRH) agonist ${ }^{6}$.

The response rate to ovarian ablation in premenopausal $\mathrm{MBC}$ varied between studies and ranges from $14 \%$ to $16 \%{ }^{7}$. This response is strongly determined by hormone receptor status of the tumor. In combined estrogen receptor (ER) and progesterone receptor $(\mathrm{PgR})$ positive tumors, the response rate is around $60 \%$. On the other hand, the response rate is only $30 \%$ when one of them only (ER or PgR) is positive . $^{8}$.

When there is no evidence of hormone therapy resistance and there is no need aggressive therapy (e.g. for rapid disease control), hormonal therapy is a preferred choice for ER positive premenopausal MBC patients $^{9,10}$.

The aim of the study was to assess the efficacy and safety profile of ovarian ablation by radiation followed by letrozole in the treatment of premenopausal women with metastatic breast cancer with hormone receptor positive disease. 


$\begin{array}{ll}\text { Kasr-El-Aini Journal Of Clinical Oncology And Nuclear Medicine } & \\ \begin{array}{ll|ll}\text { Vol. } 11 \text { No. 3-4 } & 2015 & \text { Ovarian Ablation + Letrozole in Breast cancer }\end{array}\end{array}$

\section{PATIENTS AND METHODS}

This prospective single arm phase II study was conducted at the Clinical Oncology Department of Assiut University, Egypt to assess the efficacy and safety profile of radiation induced ovarian ablation followed by letrozole therapy in patients with hormone receptor positive premenopausal $\mathrm{MBC}$ as either first-line or second-line after chemotherapy treatment for metastatic disease. The study protocol was approved by the Ethics Committee of Faculty of Medicine, Assuit University, Egypt.

\section{Eligibility criteria}

Eligible patients had to meet all of the following inclusion criteria at study entry:

- Premenopausal women $\leq 50$ years if the occurrence of menstruation within the last 3 months of study entry as well as luteinising hormone ( $\mathrm{LH})$, follicle stimulating hormone (FSH) and estradiol (E2) serum levels within the premenopausal range.

- Confirmed diagnosis of MBC

- Measurable lesion (according to Response Evaluation Criteria in Solid Tumors [RECIST] ${ }^{11}$ ) or assessable bone metastases

- ER and/or PgR +ve tumor (positivity rate $\geq 1 \%$ on immunohistochemical analysis)

- Eastern Cooperative Oncology Group (ECOG) performance status of 0 or 1

- Adequate bone marrow, hepatic and renal functions.

- Informed consent to participate in the study.

Treatment with bisphosphonate was allowed as well as palliative radiotherapy to bone metastases. However, irradiated bony lesions were not used to assess response to the study protocol.

\section{Exclusion criteria included:}

- Central nervous system metastasis.

- Previous hormonal therapy for MBC.

- The need for rapid tumor control using systemic chemotherapy (e.g. lymphangitis pulmonary metastases or progressive liver metastases).

- Pregnant or lactation.

\section{Clinical assessment}

At enrollment, all patients were subjected to the following: medical history, physical examination, performance status assessment, laboratory examinations including complete blood picture, liver and renal function tests, chest x-ray or computed tomography (CT) scan, abdominal ultrasound or CT scan, bone scan and brain CT scan.

Hormone level tests (LH, FSH and E2) were assessed monthly after radiotherapy until reaching postmenopausal range.

Follow-up was done by physical examination and any previous abnormal imaging studies were repeated every 3 months.

\section{Treatment plan}

After localization of the ovaries using ultrasound, eligible patients received 16 Gy divided on four fractions to the mid-plane of the pelvis by antero-posterior fields of. Radiotherapy was given with either cobalt- 60 or 15 MV photons of the linear accelerator.

Letrozole ( $2.5 \mathrm{mg}$ once a day by mouth) was initiated after the serum levels of LH, FSH and E2 were within the postmenopausal range. All patients continued the treatment until disease progression or the occurrences of unacceptable adverse events.

\section{Assessment of response}

Tumor response was evaluated according to RECIST. For the evaluation of non-measurable disease such as bone lesions, complete response was defined as the disappearance of all non-measurable lesions; stable disease was defined as persistence of non-measurable lesions and progressive disease referred to overall progression of existing non-measurable lesions or the appearance of new lesions.

\section{Toxicity evaluation}

Adverse events during treatment and follow-up were assessed according to National Cancer Institute Common Terminology Criteria for Adverse Events (NCI-CTCAE), v. 4.

\section{Statistical analysis}

The study was designed to have a minimal evaluable sample size of 30 patients for the low incidence of advanced breast cancer in young women. Baseline patient 
characteristics were summarized using descriptive statistics. The primary end point of the study was response rate. Secondary end points were progressionfree survival (PFS), overall survival (OS) and prognostic factors of PFS. Progression-free survival was defined as the interval between the date of first treatment dose of letrozole and the date of progression or death from any cause. Overall survival was defined as the interval between the date of first treatment dose of letrozole and the date of death from any cause. Progression-free survival and OS were estimated by using the Kaplan-Meier method. Comparisons of PFS were estimated by using Log-rank test. A statistically significant difference was defined as $\mathrm{p}<0.05$. All statistical analyses were performed using SPSS software version 21 (SPSS, Chicago, IL).

\section{RESULTS}

\section{Patients and tumor characteristics}

Between May 2010 and March 2013, 38 participants were enrolled on study. Thirty-five patients were considered evaluable for response and toxicity. Three patients were excluded from analysis because they were postmenopausal.

Patient and disease characteristics are summarized in Table 1.

There were 4 patients who received no adjuvant treatment because they were stage IV at presentation. Patients with HER2/neu positive did not receive trastuzumab therapy due to unavailability of the drug. Fourteen $(40 \%)$ patients received paclitaxel + gemcitabine for MBC before enrollment and 21 (60\%) patients received ovarian ablation and letrozole as first-line treatment for MBC. All evaluable patients had achieved postmenopausal hormonal levels after radiotherapy and before receiving letrozole. The median time to reach postmenopausal hormonal serum levels after radiotherapy was 5 months.

Ten patients received intravenous bisphosphonate therapy concurrent with protocol treatment and three patients received palliative radiotherapy during protocol treatment. The median duration of letrozole therapy was 11 months (range, 5- 30) and the median duration of follow-up was 24 (range, 5- 42) months.

\section{Response to treatment}

Clinical response is shown in Table 2.

Patients with progressive disease were switched to cisplatin-based chemotherapy.

The median PFS for the whole group was 7 months. The difference in PFS according to studied variables is shown in Table 3.

One metastatic site, disease-free interval $>24$ months and hormonal therapy (ovarian ablation+ letrozole) as a first-line therapy for metastatic disease were associated with significantly longer PFS $(p=0.04, p=0.01$ and $p=0.003$; respectively).

The median OS of the whole group was 18 months.

\section{Adverse events}

Adverse events are shown in Table 4.

Treatment was not discontinued due to adverse events in any patient.

\section{Table 1: Patients and tumor characteristics}

\begin{tabular}{|c|c|c|}
\hline Characteristic & n. & $\%$ \\
\hline \multicolumn{3}{|l|}{ Age } \\
\hline Median (range) & \multicolumn{2}{|c|}{$40.1(29-49)$} \\
\hline \multicolumn{3}{|c|}{ Eastern Cooperative Oncology Group (ECOG) Performance status } \\
\hline 0 & 20 & 57.1 \\
\hline 1 & 15 & 42.9 \\
\hline \multicolumn{3}{|l|}{ Hormonal subgroup status } \\
\hline $\mathrm{ER}+\mathrm{PR}+$ & 15 & 42.9 \\
\hline $\mathrm{ER}+\mathrm{PR}-$ & 12 & 34.3 \\
\hline ER-PR+ & 8 & 22.9 \\
\hline \multicolumn{3}{|l|}{ HER2/neu status } \\
\hline Positive & 10 & 28.6 \\
\hline Negative & 18 & 51.4 \\
\hline Unknown & 7 & 20 \\
\hline \multicolumn{3}{|l|}{ Number of metastatic sites } \\
\hline 1 & 18 & 51.4 \\
\hline 2 & 11 & 31.4 \\
\hline$\geq 3$ & 6 & 17.1 \\
\hline \multicolumn{3}{|l|}{ Metastatic site } \\
\hline Bone only & 11 & 31.4 \\
\hline Bone + others & 13 & 37.1 \\
\hline Liver & 6 & 17.1 \\
\hline Lung & 15 & 42.9 \\
\hline Soft tissue \& lymph nodes & 8 & 22.9 \\
\hline
\end{tabular}




\begin{tabular}{lcc}
\hline Disease-free interval (months) & \\
Median (range) & $29(0-48)$ \\
\hline Hormonal therapy & 31 \\
Adjuvant tamoxifen & 21 & 88.6 \\
First-line in metastatic setting & 60 \\
Second-line in metastatic setting & 40 \\
\hline
\end{tabular}

$E R=$ estrogen receptor, $P R=$ progesterone receptor, $H E R 2 /$ neu= human epidermal growth factor receptor 2

Table 2: Response rate after ovarian ablation by radiation and letrozole treatment of metastatic breast cancer patients

\begin{tabular}{lcc}
\hline Response & n. & \% \\
\hline Partial response & 12 & 34.3 \\
\hline Stable disease & 11 & 31.4 \\
\hline Progressive disease & 12 & 34.3 \\
\hline
\end{tabular}

Table 3: The relation between variables and progressionfree survival (PFS) after ovarian ablation by radiation and letrozole in 35 metastatic breast cancer patients

\begin{tabular}{|c|c|c|c|}
\hline \multirow{2}{*}{ Variable } & \multicolumn{2}{|c|}{ PFS (months) } & \multirow{2}{*}{$\begin{array}{c}\mathbf{P} \\
\text { value }\end{array}$} \\
\hline & Median & $95 \% \mathrm{CI}$ & \\
\hline \multicolumn{4}{|c|}{ Hormonal receptor status } \\
\hline $\mathrm{ER}+\mathrm{PR}+$ & 8 & $7.3-8.7$ & 0.251 \\
\hline ER+ PR- & 8 & $7.5-8.5$ & \\
\hline ER-PR+ & 6 & $5-6.8$ & \\
\hline \multicolumn{4}{|c|}{ Visceral metastases } \\
\hline Yes & 8 & $7.4-8.6$ & 0.371 \\
\hline No & 6 & $5.3-6.7$ & \\
\hline \multicolumn{4}{|c|}{ Number of metastatic sites } \\
\hline 1 & 8 & $7.5-8.5$ & $<0.04$ \\
\hline 2 & 6 & $4.4-7.6$ & \\
\hline 3 & 6 & $5.4-6.6$ & \\
\hline \multicolumn{4}{|c|}{ Disease free interval } \\
\hline$>24$ months & 8 & $7.6-8.4$ & $<0.01$ \\
\hline$<24$ months & 5 & $4.2-6.8$ & \\
\hline \multicolumn{4}{|l|}{ Hormonal therapy } \\
\hline First line & 8 & $7.6-8.4$ & $<0.003$ \\
\hline Second line & 6 & $5.2-6.8$ & \\
\hline \multicolumn{4}{|l|}{ HER2/neu status } \\
\hline Negative & 8 & $7.6-8.4$ & $<0.02$ \\
\hline Positive & 5 & $4.5-7.5$ & \\
\hline
\end{tabular}

$P F S=$ progression-free survival, $C I=$ confidence interval, $E R=$ estrogen receptor, $P R=$ progesterone receptor"

Table 4: Adverse events of ovarian ablation by radiation followed by letrozole in 35 metastatic breast cancer patients

\begin{tabular}{lcccc}
\hline \multirow{2}{*}{ Toxicity } & \multicolumn{2}{c}{ Grade I } & \multicolumn{2}{c}{ Grade II } \\
\cline { 2 - 5 } & n. & \% & n. & $\%$ \\
\hline Nausea \& vomiting & 3 & 8.6 & 0 & 0 \\
\hline Diarrhea & 2 & 5.7 & 0 & 0 \\
\hline Abdominal pain & 3 & 6.8 & 0 & 0 \\
\hline Hot flushes & 5 & 14.3 & 2 & 5.7 \\
\hline Lower limb edema & 3 & 6.8 & 0 & 0 \\
\hline Arthralgia & 2 & 5.7 & 0 & 0 \\
\hline
\end{tabular}

\section{DISCUSSION}

Targeting ER is an established treatment strategy in breast cancer patients for decades ${ }^{12}$.

In hormone receptor positive breast cancer (early and late stages), endocrine therapy is a preferred treatment aiming at decreasing the circulating estrogen level. Different forms of endocrine treatment aims at reducing the production of estrogen by the ovaries, a major source of estrogen, or decreasing the function of estrogen ${ }^{13}$.

One of the endocrine treatment modalities is aromatase inhibitors (AIs) which are effective in the post-menopausal setting, but not in the pre-menopausal one because of the continued production of estrogen by the ovaries ${ }^{14}$. Induction of menopausal state may be achieved by suppressing/ablating ovarian function by surgery, radiotherapy or LHRH agonist with no enough evidence for the superiority of any of these modalities ${ }^{15}$.

Evidence from randomized clinical trials showed that ovarian ablation yields similar results to that of tamoxifen when given as first-line in premenopausal $\mathrm{MBC}^{16}$. Similarly, the uses of LHRH agonist or oophorectomy in premenopausal MBC yield more or less similar results in terms of response and survival ${ }^{17}$. The same applies for oophorectomy when compared to ovarian radiotherapy. Both modalities resulted in equal outcome ${ }^{18}$.

In the present study, evaluation of efficacy of ovarian ablation by radiotherapy followed by letrozole for premenopausal patients with hormone receptorpositive MBC was done. The partial response was achieved in $34.3 \%$ of patients, clinical benefit rate (CBR) was $65.7 \%$, the median PFS was 7 months and the median OS was 18 months. These results are close to those reported by Yao et al who investigated LHRH agonist plus letrozole as $2^{\text {nd }}$ line hormonal therapy in premenopausal advanced breast cancer ${ }^{19}$. They reported an overall response rate (ORR), CBR and PFS of $21.1 \%, 71.1 \%$ and 10 months, respectively ${ }^{19}$. In another study, letrozole plus goserelin as $1^{\text {st }}$ line in very young patients with advanced breast cancer, yieleded ORR, CBR and PFS of $25.7 \%, 65.7 \%$ and 9.6 months respectively ${ }^{20}$. Again, the results were close to ours, but we had a higher partial response which may be due to the higher percentage of bone metastases (69\%).

Letrozole plus LHRH agonist when used in premenopausal MBC showed a comparable efficacy to that of letrozole alone as $1^{\text {st }}$ line in postmenopausal patients $^{21}$.

Ovarian function suppression to create a postmenopausal state facilitates the response to AIs reducing peripheral estrogen production. Among the 


Vol. $11 \mid$ No. 1-2 $2015 \quad$ Mostafa H.G.

options available for ovarian ablation, radiation is a reasonable option ${ }^{22}$. This is specially true in resourcelimited settings.

In the current study $40 \%$ of included patients received prior cytotoxic therapy for $\mathrm{MBC}$ and were switched to endocrine therapy because of disease progression. Patients treated with endocrine therapy as $1^{\text {st }}$ line for $\mathrm{MBC}$ had a significant longer PFS. In addition, patients with one metastatic site and $>24$ months disease-free interval had significantly favorable prognosis related to PFS which is in agreement with the predicted association of number of metastatic sites and worse PFS in the study done by Liu et $\mathrm{al}^{20}$.

Peron et al. identified a group of patients with good prognostic factors (tumor grade $<3$ and no visceral metastases) for whom median PFS was 15.5 months when treated with endocrine therapy as a $1^{\text {st }}$ line for $\mathrm{MBC}^{23}$.

The type of hormone receptor expression (ER/PgR) is a predictive of PFS after endocrine therapy. ER-ve/ PgR+ve tumors had a lower PFS and a higher risk of relapse than ER+ve tumors in the present study but the difference was not statistically significant. The study done by Chan et al. demonstrated similar results ${ }^{24}$.

Toxicity of the current therapy was not severe; all adverse events reported were grade 1 or 2 . Hot flushes, abdominal pain and nausea/vomiting were reported as the most common side effects observed among patients treated with radiation ablation followed by letrozole. These results are comparable to the results of the study of Liu et $\mathrm{al}^{20}$.

In conclusion, the study results suggest that combination therapy with radiation ovarian ablation followed by letrozole is a safe and effective treatment for premenopausal patients with hormone receptor-positive MBC. The treatment is feasible as endocrine therapy in premenopausal MBC patients particularly when tamoxifen is ineffective. Further studies are required to support these results.

\section{REFERENCES}

1. Ferlay J, Shin HR, Bray F, et al. Estimates of world wide burden of cancer 2008: GLOBOCAN 2008. Int J Cancer. 2010;127: 2893 -917.

2. Anderson WF, Chatterjee N, Ershler WB, et al. Estrogen receptor breast cancer phenotype in the surveillances, epidemiology and end results data. Breast Cancer Res Treat. 2007;76: 27- 36

3. Cardoso F, Loibl S, Pagani O, et al. The European Society of Breast Cancer specialists recommendations for the management of young women with breast cancer. Eur J Cancer. 2012;48: 4455-4477.
4. Martinez-Prieto M, Flores de la Torre CB, Rivere Rivera $\mathrm{S}$, et al. [Hormonal therapy in metastatic breast cancer]. Ginecol Obstet Mex 2009; 77: 482 -486.

5. Carison RW, Anderson BO, Burstein HJ, et al. Invasive breast cancer. J Natl Compr Canc Netw. 2007;5: 246 -312.

6. The Adjuvant Breast Cancer Trials Collaborative Group. Ovarian ablation or suppression in premenopausal early breast cancer: results from the international adjuvant breast cancer ovarian ablation or suppression randomized trial. J Natl Cancer Inst. 2007;99:516- 525.

7. Robertson JF and Blamey RW. The use of gonadotrophinreleasing hormone $(\mathrm{GnRH})$ agonist in early and advanced breast cancer in pre-and perimenopausal women. Eur J Cancer. 2003;39:861- 869.

8. Osborne CK, Yochmowitz MG, Knight WA $3^{\text {rd }}$, et al. The value of estrogen and progesterone receptors in the treatment of breast cancer. Cancer. 1980;46:2884- 2888.

9. Cardoso F, Costa A, Norton L, et al. 1st International consensus guidelines for advanced breast cancer (ABC 1). Breast. 2012; 21:242- 252.

10. Cardoso F, Fallowfield L, Costa A, et al. Locally recurrent or metastatic breast cancer: ESMO Clinical Practice Guidelines for diagnosis, treatment and follow-up. Ann Oncol. 2011;22:vi25-30.

11. Therasse P, Arbuck SG, Eisenhauer EA, et al. New guidelines to evaluate the response to treatment in solid tumors. European Organization for Research and Treatment of Cancer, National Cancer Institute of the United States, National Cancer Institute of Canada. J Natl Cancer Inst. 2000;92:205- 216.

12. Di Leo A and Malorni L. Polyendocrine treatment in estrogen receptor-positive breast cancer: a "FACT" yet to be proven. J Clin Oncol. 2012; 30:1897-1900.

13. Masuda N, Sagara Y, Kinoshita T, et al. Neoadjuvant anastrazole versus tamoxifen in patients receiving goserelin for premenopausal breast cancer (STAGE): a double-blind, randomized phase 3 trial. Lancet Oncol. 2012;13:345-352.

14. Paridaens R, Therasse P, Dirix L, et al. First line hormonal treatment (HT) for metastatic breast cancer (MBC) with examestane (E) or tamoxifen ( $\mathrm{T}$ ) in postmenopausal patients (pts); A randomized phase III trial of the EORTC Breast Group. J Clin Oncol. 2004;22:515.

15. Christiant A, Di Lascio S and Pagani O. Hormonal therapies in young breast cancer patients: when, what and for how long? J Thorac Dis. 2013; 5:S36- 46.

16. Sawka CA, Pritchard KI, Shelley W, et al. A randomized crossover trial of tamoxifen versus ovarian ablation for metastatic breast cancer in premenopausal women: a report of the National Cancer Institute of Canada Clinical Trials Group (NCIC CTG) trial MA.1. Breast Cancer Res Treat. 1997;44: 211 -215.

17. Taylor CW, Green S, Dalton WS, et al. Multicenter randomized clinical trial of goserelin versus surgical ovariectomy in premenopausal patients with receptorpositive metastatic breast cancer: an intergroup study. J Clin Oncol. 1998;16: 994- 999. 
18. Early Breast Cancer Trialists' Collaborative Group. Polychemotherapy for early breast cancer: an overview of the randomized trials. Lancet. 1998;352:930 -942.

19. Yao S, Xu B, Li Q, et al. Goserelin plus letrozole as first- or second-line hormonal treatment in premenopausal patients with advanced breast cancer. Endocrine J. 2011;58:50 9-516.

20. Liu X, Qu H, Cao W, et al. Efficacy of combined therapy of gosereline and letrozole on very young women with advanced breast cancer as first-line endocrine therapy. Endocrine J. 2013;60:819 -828.

21. Park IH, Ro J, Lee KS, et al. Phase II parallel group study showing comparable efficacy between premenopausal metastatic breast cancer patients treated with letrozole plus goserelin and postmenopausal patients treated with

\section{Ovarian Ablation + Letrozole in Breast cancer}

letrozole alone as first-line hormone therapy. J Clin Oncol 2010; 28: 2705- 2711

22. Bese NS, Iribas A, Dincan A, et al. Ovarian ablation by radiation therapy: is still an option for the ablation of ovarian function in endocrine responsive premenopausal breast cancer patients? Breast. 2009;18:304- 308.

23. Peron J, Tredan O, Ray-Coquard I, et al. First-line endocrine therapy alone could be a reasonable treatment option for hormone-positive, HER2-positive metastatic breast cancer. Bull Cancer. 2012;99:18 -25.

24. Chan M, Chang M, Gonzalez R, et al. Clinical outcomes of estrogen receptor (ER)-negative and progesterone receptor (PgR)-positive invasive breast cancer. J Clin Oncol. 2014; 32:567. 